\title{
New life planned for British plasma science
}

London. The Science and Engineering Research Council (SERC) and industry are considering initiatives to revitalize British plasma research. The intention is to bridge the gap between fusion research, which has seen a dip in funding in recent years, and other areas of plasma science, particularly those with industrial applications. Although glad of the attention that the wider field of plasma science is now getting, some academic researchers are concerned about placing their future entirely in the hands of industry.

Fusion energy programmes have long dominated plasma research in Britain, with the largest groups at Atomic Energy Authority's (AEA) Culham laboratory, home of the Joint European Torus (JET), and at Imperial College London. AEA now spends $£ 10.8$ million (US\$21 million) on fusion research, of which $£ 400,000$ goes to universities. SERC spends about $£ 250,000$ annually on plasma research related to fusion.

However, organizational changes at the AEA have left some groups stranded. The mechanisms to take up the slack in supporting work peripheral to fusion, but considered worthy of study in its own right, have never really been established. Similarly, there has been no increase in support for the study of non-equilibrium and impure plasmas, fields that have grown in recent years.

"[The level of] support for plasma physics in Britain is sub-critical", says David Burgess of Imperial College. "There are good, strong groups that cannot move from one area to another."

The SERC is considering a plasma science initiative, proposed by Burgess, to cover plasmas with interesting technological features as well as areas spun off from the fusion studies. At the same time, researchers emphasize that such applications are often derived from fundamental work, which cannot be allowed to wither away.

The technologies in question, identified in a report from the independent Centre for the Exploitation of Science and Technology $(\mathrm{CEST})^{*}$, include using plasmas in manufacturing, particularly in modifying surfaces, and in environmental clean-up, where they can be used to destroy low levels of toxic waste. But industry needs better methods for modelling plasmas before it can scale up experimental procedures.

The report says that more needs to be done to link industry and university scientists, to increase awareness of what plasmas can do and to transfer skills. Although researchers are keen for this sort

\section{University wants to buy journals directly}

London. In an attempt to stem the rising cost of scientific journals, the University of Kent at Canterbury is considering creating its own subscription agency as a means of getting more for its money. By buying journals direct from publishers, the library and university departments can take advantage of the agency discount offered by some publishers and avoid the mark-up, or service charge, usually added to subscriptions by commercial agencies. University administrators are discussing with publishers the viability of such a scheme.

Cyril Isenberg, a Kent physicist, says that it should be possible to save tens of thousands of pounds despite the costs involved in running the office. The university now spends $£ 300,000$ a year on journals.

However, it may be that Kent has underestimated the costs and manpower involved. The agencies operate on a narrow margin, earning a discount from publishers for taking on the burden of dealing with a multitude of customers. Although the agencies expect to earn a profit by practising economies of scale, some of the smaller operations are said to be struggling. The universities are charged for the service, which gives them the advantage of buying from one source and a certain amount of credit.
Journal publishers appreciate the problems that inflation and rising subscription prices have created for university libraries and encourage any efforts by libraries to improve the situation. However, they are unwilling to anger the agencies, which hold a very powerful place in the publishing chain, and privately they doubt whether university agencies would be offered the same discount.

Meanwhile, other British universities the existing system. Both the colleges of the University of London and a group of universities in the south of England have bulkorder arrangements with the agencies that offer them a greater discount. When cancellations have been unavoidable, obtaining individual papers through special databases has helped them to fill the gaps.

Although the British Library's document supply centre in Boston Spa dominates the British market, such services are of increasing importance to libraries. B.H. Blackwell, a journal supply agency based in Oxford, has just announced an agreement with a US company, CARL Systems, that will make available a commercial document supply service derived from a base of 15,000 to 20,000 titles.

Ian Mundell have attacked the problem by working within of exchange, they do not want to sacrifice their independence.

"I can understand why CEST regards these areas as so important, but you have to distinguish those that industry should pay for and those that, as part of the scientific future of this country, are down to the SERC", says Burgess. He said that industry must pay the going rate for whatever it wants that is now done at universities.

Ian Mundell

* Industrial plasmas: focusing UK skills on global opportunities (£30), CEST, 5 Berners Road, London

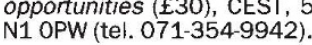

\section{Big projects eat up NASA's future budgets}

Washington. Despite the recent shift of the National Aeronautics and Space Administration (NASA) towards smaller and cheaper missions, nearly all the agency's budget is already committed to large projects that would be politically difficult to kill, accord-

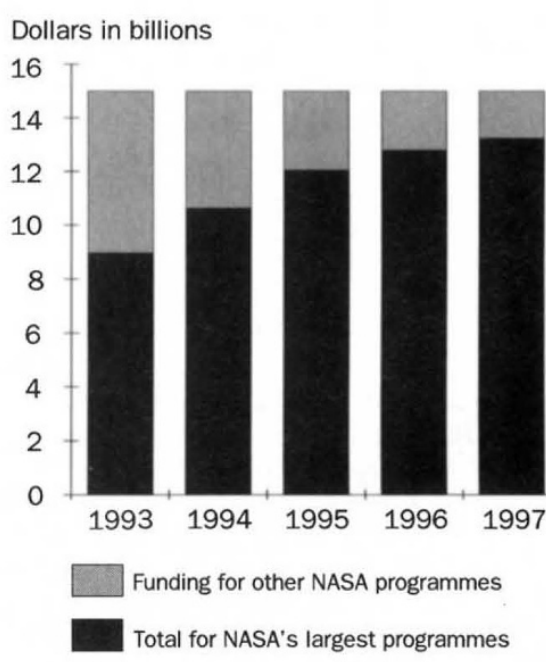

ing to a congressional analysis released last week. At current levels, projects such as the space shuttle, the space station and the Earth observing system will consume nearly 90 per cent of NASA's funding by 1997 , leaving little money for a new crop of smaller missions such as a proposed Pluto probe (see Nature 358, 701; 1992).

Auditors from the congressional General Accounting Office (GAO) assume that NASA's budget will remain near its current level of $\$ 15$ billion for the next five years, a projection that seems increasingly realistic, and they criticize NASA for ignoring this fact in its five-year plan. Agency officials say that they are working on a new plan that would lower the cost of the large programmes.

Christopher Anderson 